\title{
O PIONEIRISMO DAS ALUNAS DA FACULDADE DE DIREITO DE PE- LOTAS-RS: INCLUSÃO FEMININA ATRAVÉS DA EDUCAÇÃO
}

\author{
PIONEERS OF WOMEN STUDENTS FROM LAW COLLEGE OF PELO- \\ TAS-RS: FEMININE INCLUSION THROUGH EDUCATION
}

\author{
Valesca Brasil Costa ${ }^{1}$
}

Recebido em: 26/03/2011

Aprovado em: 11/06/2012

\section{RESUMO}

Este trabalho teve como objetivo revisitar a memória das alunas pioneiras da Faculdade de Direito de Pelotas-RS. A primeira fase da pesquisa foi a revisão bibliográfica, a partir de algumas obras sobre História da Educação; e Ensino Jurídico; a segunda fase foi desenvolvida na Biblioteca Pública Pelotense e na Faculdade de Direito de Pelotas. O trabalho recupera a história da Faculdade de Direito de Pelotas por meio das mulheres, as quais estão inscritas na história da mesma, como: Heló́sa do Nascimento (primeira professora de Direito do Brasil); Sophia Galanternick, (primeira mulher Promotora Pública no RS); Maria Soares, (juíza de Direito no interior do RS); Rosah Russomano, (primeira mulher a receber título de Professora Emérita na UFPel); Gilda Russomano (que deu a honra de ser a primeira mulher no Brasil a ser diretora de uma Faculdade de Direito). Assim, se percebe, neste momento da pesquisa, que essas mulheres superaram, por meio da educação, o preconceito e a limitação impostos por uma sociedade patriarcal e foram pioneiras em suas profissões no campo jurídico.

Palavras-chave: História da Educação; Mulher; Direito; Precursoras; Inclusão.

\section{Introdução}

Esta pesquisa aborda a presença feminina na Faculdade de Direito de Pelotas-RS, buscando fazer uma leitura das primeiras alunas que ingressaram no Curso de Direito, em tal faculdade, e que se destacaram em suas profissões, como professoras de Direito, Escritoras, Historiadoras, Juízas de Direito, Promotoras Públicas, chegando até

\begin{abstract}
This work had the objective of revisiting the memory of the pioneer female students from the Law School of the municipality of Pelotas, in the state of Rio Grande do Sul, Brazil. The first phase of the survey was a literature review from a few works on the History of Education and Legal Education. The second phase was developed at the Public Library of Pelotas and at the Law School of Pelotas. The work restores the history of the Law School of Pelotas via women who are part of this history, such as Heloisa do Nascimento (the first Law professor in Brazil), Sophia Galanternick (the first woman to be a District Attorney in the state of Rio Grande do Sul), Maria Soares (Law Judge in the countryside of the state of Rio Grande do Sul), and Rosah Russomano (who gave the honor of being the first woman in Brazil to be a Law School Dean). Thus, we could notice at this time of the survey that these women overcame through education the prejudice and the limitation imposed by a patriarchal society, and were pioneers in their professions in the Legal field.
\end{abstract}

Keywords: History of Education; Woman; Law; Precursors; Inclusion.

membros constituintes do corpo técnico da ONU.

O trabalho tem por objetivos revisitar a memória das alunas pioneiras da Faculdade de Direito de Pelotas-RS; observar a importância do contexto histórico da cidade de Pelotas-RS como fator local, tendo em contrapartida a situação histórica mundial; e, ainda, salientar o importante papel da educação para a inclusão social da mulher, em es-

'Doutoranda em Educação pelo Programa de Pós-Graduação em Educação da Universidade do Vale do Rio dos Sinos (UNISINOS), Brasil. Bolsista CAPES-PROEX. E-mail: valescacosta@gmail.com. 
pecial, em um espaço tão masculinizado como o espaço jurídico.

Por se tratar de uma pesquisa em História da Educação, foi considerado fundamental um estudo prévio sobre qual metodologia seria usada, optandose pela história oral. É relevante observar que esta é uma pesquisa relacionada com diferentes áreas, não se limitando, dessa forma, a técnicas pré-determinadas. É um momento novo na pesquisa em História da Educação, momento de transição, em que novas condições já estão configuradas, considerando-se especialmente a história daqueles que, durante muito tempo, ficaram excluídos da história, como se dá no caso das mulheres.

Para isso, é preciso considerar que os trabalhos sobre História da Educação, que envolvem, em seu ponto principal, estudos relacionados a mulheres e educação, são muito recentes, reforçados pela chamada Nova História Cultural, que direcionou o olhar das pesquisas históricas, observando os aspectos sociais, culturais e econômicos de uma sociedade.

Mais recentemente, tanto no Brasil como em outros países, a Nova História e particularmente a Nova História Cultural, tem influenciado os pesquisadores para que investiguem temas antes considerados menos nobres no interior da própria História da Educação. A "revolução" provocada no campo da história, sobretudo pela "Escola dos Annales" e, posteriormente, pelo se convencionou denominar de Nova História, que buscou alargar os objetos, as fontes e as abordagens utilizados buscou alargar os objetos, as fontes e as abordagens utilizados tradicionalmente na pesquisa autobiográfica, aos poucos influenciou os historiadores da educação (LOPES, 2001, p. 39).

Assim, se na história cultural existiu essa forte relação da história com a antropologia, há também outra novidade: agora se busca focar na mi- cro-história, ou seja, aquela história dos acontecimentos cotidianos, em escala menor que até então se fazia. No caso desta pesquisa, pretende-se focar um grupo de mulheres que superaram, através da educação, limitações e conseguiram ingressar em uma carreira tipicamente masculina: o espaço jurídico em uma sociedade no interior do Rio Grande do Sul.

Os antropólogos ofereciam um modelo alternativo, a ampliação do estudo de caso onde havia espaço para a cultura, para a liberdade em relação ao determinismo social e econômico, e para os indivíduos, rostos na multidão. $\mathrm{O}$ microscópio era uma alternativa atraente para o telescópio, permitindo que experiências concretas, individuais ou locais, reingressassem na história (BURKE, 2005, p. 61).

A primeira fase da pesquisa constituiu-se da revisão bibliográfica, em que as obras pesquisadas tratavam sobre os temas em estudo, como: história da educação; história oral; educação e a mulher; antropologia e ensino jurídico. Destacamos que, nessa fase do trabalho, a utilização da pesquisa (auto) biográfica foi de suma importância, uma vez que era preciso remontar a trajetória da vida das primeiras mulheres que cursaram a Faculdade de Direito de Pelotas.

Nesse sentido, Maria Helena Barreto Abrahão, expressou muito bem, em seu artigo "Pesquisa (auto) biográfica - tempo, memória e narrativas", a importância desse método de pesquisa para dar ao pesquisador a verdadeira dimensão e a noção da realidade dos fatos por ele pesquisados.

A pesquisa (auto) biográfica é uma forma de história autorreferente, portanto plena de significado, em que o sujeito se desvela, para si e para os demais. Produzir pesquisa (auto) biográfica significa utilizar-se do exercício da memória como condição sine qua non. A memória é elemento-chave do trabalho com pesquisa (auto) biográfica, 
em geral: História de vida, Biografias, Autobiografias, Diários, Memórias. A pesquisa (auto) biográfica, embora se utilize de diversas fontes, tais como narrativas, história oral, epistolas foto, vídeos, filmes, documentos, utiliza-se do exercício da rememoração, por excelência. Esta é componente essencial na característica do(a) narrador(a) na construção/reconstrução de sua subjetividade. Esta é componente essencial com que o pesquisador trabalha para poder (re)construir elementos de analise que possam auxiliá-lo na compreensão de seu estudo, ao tentar articular memória e conhecimento, procurando edificar uma "arqueologia da memória (ABRAHÃO, 2004, p. 202).

A segunda fase da pesquisa foi realizada na Faculdade de Direito de Pelotas, mais especificamente, no Centro Acadêmico Ferreira Viana, na biblioteca da mesma faculdade e, ainda, na Bibliotheca Pública Pelotense. Cabe observar que o material encontrado mostrou-se rico em informações, o que possibilita observar o quanto é essencial a preservação desses registros, como considerou Michelle Perrot (2007) em seu livro "Minha História das Mulheres", há uma séria carência em arquivos sobre a trajetória das mulheres, o que, por sua vez, dificulta escrever sua história.

Para escrever a história, são necessárias fontes, documentos, vestígios. E isso é uma dificuldade quando se trata da história das mulheres. Sua presença é frequentemente apagada, seus vestígios, desfeitos, seus arquivos, destruídos. Há um déficit, uma falta de vestígios. Inicialmente, por ausência de registros. $\mathrm{Na}$ própria língua. A gramática contribui para isso. Quando há mistura de gêneros, usa-se o masculino plural: eles dissimula elas. No caso de greves mistas, por exemplo, ignora-se quase o número de mulheres (PERROT, 2007, p. 21).

Como foi considerado anteriormente, o objetivo deste trabalho é revisitar a memória das alunas pioneiras da Faculdade de Direito de Pelotas-RS.
Para tanto, a pesquisa foi amparada na análise dos documentos que registraram esse período da história das mulheres que fizeram parte da memória da Faculdade de Direito. As informações foram recolhidas a partir da análise de: jornais (no caso o Jornal Diário Popular); atas do Centro Acadêmico Ferreira Viana que mencionavam o nome dessas alunas; fotografias e material pesquisado na dissertação sobre a Faculdade de Direito; documentos públicos.

Dessa maneira, o que se pretende trazer para este artigo são as falas, além de dar vez e voz às mulheres e enaltecê-las, pois, durante muito tempo, elas ficaram excluídas da história, e, no caso das pesquisadas, ultrapassaram os limites do seu tempo e foram pioneiras no espaço jurídico, um espaço tipicamente masculino.

Na obra de Ecléa Bosi, intitulada "Memória e Sociedade: lembranças de velhos", a autora faz toda uma análise, passando por Halbwachs, herdeiro da sociologia francesa, que considera como ponto fundamental a precedencia do fato social e do sistema social, infuenciando sobre os fenômenos de ordem psicológica: "a lembrança é a sobrevivência do passado. O passado, conservando-se no espírito de cada ser humano, aflora à consciência na forma de imagens-lembranças" (BOSI, 1994, p. 53).

\section{Apontamentos sobre a história da mulher e a sua relação com a educação}

O estudo da relação que há entre a história das mulheres e a educação é fundamental para que se consiga compreender e analisar o tema proposto por este trabalho, sobre a presença feminina na Faculdade de Direito de Pelotas-RS. Isso por que, para as mulheres conseguirem chegar ao espaço jurídico, precisavam, como instrumento básico, do acesso à educação, o que, a princípio, pode parecer tarefa simples, mas durante muito tempo foi cerceado às mulheres.

O papel e imagem da mulher na sociedade sofreram com vários este- 
reótipos, a ponto de ela ser considerada apenas por sua possibilidade reprodutora, como bem se observou na obra intitulada o "Mundo de Sofia", a qual tem considerações sobre a visão que o filósofo Aristóteles tinha sobre a mulher:

Fundamentalmente, Aristóteles achava que faltava alguma coisa à mulher. Para ele, a mulher era 'um homem incompleto'. Na reprodução, a mulher é passiva e receptora, enquanto o homem é ativo e produtivo. Por essa razão é que - segundo Aristóteles - o filho do casal herdava apenas as características do pai (GAARDEN, 1991, p. 128).

No entanto, muitos são unânimes em constatar que as diferenças biológicas entre homens e mulheres existem, devem ser respeitadas, mas jamais usadas como artifício de defesa para legitimar a dominação masculina, que se dá pelas construções sociais que limitam o acesso das mulheres a instrumentos de inclusão social, de maneira que se desenvolvam e se completem como seres sociais.

É necessário demonstrar que não são propriamente as características sexuais, mas a forma como essas características sexuais são representadas ou valorizadas, aquilo que se diz ou se pensa sobre elas que vai constituir, efetivamente, o que é feminino ou masculino em dada sociedade, em um dado momento histórico (LOURO, 1997, p. 21).

"Gênero" foi durante muito tempo um termo usado para se trabalhar unicamente com o contexto das diferenças biológicas entre o sexo, ou seja, gênero feminino ou gênero masculino. Joan Scott, em seu trabalho intitulado "Gênero: uma categoria útil da analise histórica", refere que a utilização "gênero" foi introduzida pelas feministas americanas, que centravam sua essência não nas determinações biológicas e sim no caráter social das diferenças entre os sexos.
Mais recentemente - demasiado recente para que pudesse encontrar seus caminho nos dicionários ou Encyclopedia of Social Sciencies - as feministas começaram a utilizar a palavra 'gênero' mais seriamente, num sentido mais literal, como maneira de se referir à organização social da relação entre sexos (SCOTT, 1999, p. 05).

Dentre as primeiras profissões nas quais as mulheres conseguiram espaço no campo de trabalho, a educação ganha destaque. Embora ainda haja correspondência direta entre a docência feminina e o fato da maternidade, bem como se dá com a enfermagem, conquistar outras áreas, como a jurídica tida como tipicamente masculina, seria ainda um árduo caminho a percorrer: "O acesso às profissões ligadas ao direito foi mais difícil, não se reconhecendo aptidões jurídicas nas mulheres, a titulo individual. $\mathrm{O}$ direito aparecia como um apanágio masculino" (PERROT, 1998, p. 110).

Assim, constatar-se-á que, mesmo a mulher abrindo espaços na sociedade através da educação, ainda haverá, nos objetivos buscados, a contribuição feminina como ponto chave na formação, instrução e sustentação da família nos moldes cristãos:

É natural em um país de formação ocidental cristã como o Brasil do séc. XIX que ocorra uma vinculação desta ideologia à necessidade de educação da mulher. Procura-se assim em parâmetros evangélicos a justificativa para tal empreendimento (TAMBARA, 1997, p. 83).

\section{A presença feminina no Curso de Direito de Pelotas}

A relação entre as mulheres pelotenses e a educação se dá há longo tempo. As mulheres de Pelotas não só se destacavam por sua beleza, mas também por sua refinada educação, já que muitas filhas de charqueadores tinham acesso a desenvolver seus estudos no 
Rio de Janeiro e até mesmo na Europa.

De fato, foram mulheres as de Pelotas, cheias de encanto, de refinada educação e espiritualidade. Uma delas, D. Mercedes Maciel Moreira, chegou a ser considerada, pelo pensador Gama Rosa 'a mais genial poetisa e musicista da sua época' e pelo Conde de Afonso Celso, 'a mais ilustrada e completa dama de seu tempo'. Outra - D. Maria Francisca da Costa Rodrigues da Silva, conhecida carinhosamente como Sinhá Costinha - teve seus 'dotes de rosto e de espírito louvados até na Europa (MAGALHÃES, 1981, p. 36).

Celuila Maria Mello e Silva, que ingressou na Faculdade de Direito em 1921, natural da cidade de Jaguarão e filha de Juiz de Direito, buscava seguir, na Instituição, os mesmo passos profissionais do pai. No entanto, cursou Direito até o quarto ano, quando, então, optou por abandonar os estudos e casar com o colega de aula Constantino Rodrigues de Freitas.

A Faculdade de Direito de Pelotas terá, na turma de 1936, as primeiras mulheres a se graduarem, embora seja a Primeira Faculdade de Direito do Rio Grande do Sul, datada de 1912, e, por sua vez, a sétima do Brasil. A Faculdade de Direito da UFRGS foi fundada em 17 de fevereiro de 1900, denominada, então, Faculdade Livre de Direito de Porto Alegre.

Por esse fato óbvio, notório, ninguém pôs jamais em dúvida a primazia absoluta de Natércia da Cunha Silveira como a primeira advogada, em termos cronológicos, no extremo meridional do país. A prestigiosa Faculdade de Direito de Pelotas somente em 1936 é que diplomaria três bacharelandas, entre as quais a escritora Heloísa Assumpção Nascimento (TILL, 2000, p. 256).

O fato de mulheres se matricula- rem para cursar Direito, um curso que preparava para carreira até então tipicamente masculina, foi motivo de vários comentários na cidade de Pelotas, como ilustra com a propriedade de quem viveu esse momento, a ex-aluna dessa turma, Heloisa Assumpção Nascimento, na coluna de Literatura do jornal Diário Popular de 22 de agosto de 1982:

Ao ensejo dos setenta anos de existência da nossa Faculdade de Direito, agradáveis lembranças dos bons tempos de estudante nos vem à memória. Ano de 1932. A notícia corria na cidade: quatro moças se haviam matriculado no curso jurídico. Assombro de uns, comentários variados de muitos outros, de admiração ou malícia, por ingressarem mulheres numa escola onde só rapazes estudavam, e pretenderem abraças uma profissão que àquele tempo, quase que exclusivamente aos homens pertencia (NASCIMENTO, 1982, p. 27).

Assim, aos 22 anos, no ano de 1936, Sophia Galanternick conclui os estudos na Faculdade de Direito de Pelotas e passa a advogar e a lecionar no Ginásio Pelotense, já no quinto ano de faculdade, faz seu primeiro júri, que tem muita repercussão pelo fato de ser o primeiro júri feito por uma mulher no estado do Rio Grande do Sul.

Em 1938, Sophia Galanternick recebe sua nomeação como Promotora de Justiça, sendo tal evento noticiado pelo jornal Correio do Povo, com manchete de destaque "A Mulher no Ministério Público". Por ser a primeira mulher a assumir essa posição no estado do rio Grande do Sul, ao ser designada para a comarca de Carazinho, houve grande reconhcimento, conforme considerou em entrevista a Revistas do Ministério Público do RS: "e já tinha dado no jornal a minha nomeação, aí os meus colegas me ofereceram um banquete. Os jornais, todos noticiaram, inclusive jornais de Porto Alegre noticiaram a formatura, a nomeação, foi uma alaúza 
total" (FÉLIX, 2000, p. 342).

Dentre as primeiras alunas a concluírem o curso de Direito, junto com Sophia Galanternick, estava também a professora Heloisa Assumpção Nascimento, mulher que também se destacava na intelectualidade pelotense e que narrou, em entrevista no trabalho da advogada Waleska Villar, o quanto foi motivo de curiosidade a formatura das primeiras mulheres a colarem grau em Direito na cidade de Pelotas-RS:

\begin{abstract}
A formatura teve como local o Teatro Guarani, paraninfada pelo Dr.Tancredo do Amaral Braga, lente de Direito Comercial, grande amigo dos acadêmicos. [...] Encheu-se o teatro. A maior curiosidade era pelas acadêmicas que, pela primeira vez haviam vencido o curso da Faculdade. Seus vestidos de festa representavam atraente novidade no meio do negro dos smokings, porque a toga e beca não eram usadas por formandos naquela cerimônia (VILLAR, 2004, p. 06).
\end{abstract}

No entanto, Heloisa Assumpção, dedicou-se à docência e à pesquisa em História, tendo posteriormente realizado pós-graduação em História da Arte e atuado como professora em Escolas Normais, nas disciplinas de Português e Sociologia, e também na Escola de Belas Artes e no curso de Jornalismo da UCPel.

Não resta dúvida que o papel desempenhado por essas três mulheres que se graduaram em 1936 na Faculdade de Direito de Pelotas, representa um exemplo relevante do papel que a educação tem para a inclusão social da mulher.

De qualquer modo, as três moças que haviam concluído o curso em Pelotas (houve uma colega que concluiu no Recife) ocuparam cargos na profissão e no magistério: Dra. Sofia Galanternick como primeira Promotora Pública no Rio Grande do Sul, na cidade de Carazinho; Dra. Maria Adair Soares, como primeira Juíza Municipal de Triunfo; e quem escreve estas linhas, primeira professora jurídica no País, da disciplina de Direito de Família e Sucessões, em sua própria Faculdade. [...] Mais de quarenta anos decorrem. Poucos formandos da turma de 1936 existem. Mas na memória dos que vivem, não se apagará a recordação amada e longínqua daqueles cinco anos acadêmicos da Faculdade de Direito de Pelotas (NASCIMENTO, 1982, p. 27).

Ao analisar o discurso feito pela então oradora da turma de Bacharéis em Direito da turma de 1947, constatou-se, mais uma vez, o grande destaque dado pelas discentes dessa casa. Visto ser uma das três mulheres em uma turma com nove homens, dedicou parte de seu papel de oradora para destacar a situação da mulher na sociedade daquela época.

Em discurso para colar grau, aborda sobre a "Libertação Jurídica". Mesmo que não estejamos mais sob o Código Civil de 1916, muito ainda têm as legislações atuais que evoluir sobre as questões relacionadas com condição jurídica feminina.

A mulher, contudo, acompanhando o roteiro das reivindicações cívicas, adquiriu o direito público, antes de obter outras concessões. Com sua participação ativa na vida social, sentiu-se que sua influência seria benéfica também na vida política dos povos, contribuindo para a formação sistematizada do direito. Daí, surgiu o voto feminino, mesmo pesando sobre ela o ferrete de sua suposta incapacidade. E tão significativo foi esse passo decisivo, para o alcance do objetivo final, que a mulher casada exerce aquele direito independente do consentimento marital. Se, pois, em verdade, ela coopera na política do país; se consegui aprimorar sua intelectualidade, garantindo sua subsistência, a libertação jurídica há de ser estatuída, fatal e inevitavelmente (LIMA, 1947, p. 18).

Ainda é preciso destacar outra ex-aluna da Faculdade de Direito de Pe- 
lotas, Gilda Corrêa Meyer Russomano, graduada na turma de 1951, que, ainda quando acadêmica, forma-se como Aluna Laureada. No ano de 1962, é professora catedrática de Direito Internacional Público da Faculdade de Direito de Pelotas. Sua carreira docente iniciou em 1953, como professora titular da Faculdade Católica de Filosofia, onde permaneceu até 1965.

No ano de 1961, Gilda Russomano, por unanimidade, foi indicada para fazer parte, como membro, do Instituto dos Advogados do Brasil, com sede no Rio de Janeiro, ressaltando-se o fato de ela ter conquistado, com distinção, a cadeira de Direito Internacional Público na Faculdade de Direito de Pelotas. Em uma carreira brilhante, que abarca, dentre outros títulos, membro da Comissão Interamericana de Direitos Humanos da OEA, tornando-se a única mulher a ser presidente no período de funcionamento desse órgão, de 30 anos, foi assessora especial da delegação brasileira na Conferencia da ONU de 1968, em Nova Iorque, e coube a ela dar a honra a Faculdade de Direito de Pelotas em 1969 ao ser a primeira mulher no Brasil a ser Diretora de uma instituição de Direito Federal.

Com tanto potencial e destaque, a ex-aluna da Faculdade de Direito de Pelotas, Gilda Russomano, recebeu Títulos Honoríficos de Cidadã Honorária de Pelotas, Gaúcha Honorária e Membro da Academia Brasileira de Letras Jurídicas, como bem destacou o Jornal Diário Popular de 19 de agosto de 2007, data de seu falecimento.

É interessante salientar, neste momento da contrução deste trabalho, o cruzamento entre fontes de pesquisas, como entrevistas, reportagens em jornais da época, fotografias e relatórios, deram voz a essas mulheres que tiveram tanta importância ao espaço jurídico pelotense.

Destaca-se este momento da pesquisa no qual percebeu-se diretamente a força da memória, pois é a partir dos registros passados, que os cidadãos tem viva sua história. Os gregos há mui- to tempo já perceberam, ao instituir à Deusa Mnemosyne (mãe das musas que protegem as Artes e História) o poder de conferir imortalidade aos mortais, a possibilidade de suas obras, através de registros, tornarem-se memoráveis, não morrendo jamais.

\section{Considerações finais}

Ao se chegar neste momento, pode-se afirmar que essas mulheres, as alunas pioneiras da Faculdade de Direito de Pelotas que foram fontes de pesquisa, foram um exemplo e um atestado de que a educação é um valioso instrumento de inserção da mulher na sociedade, com seu devido e merecido papel, participando diretamente da construção social e se deslocando de um papel marginal.

Dessa maneira, tem-se que este trabalho representa apenas o começo da visita da história de figuras femininas de grande importância dentro do espaço jurídico, e também a retomada da história de uma instituição consolidada pela sua relevância e qualidade no espaço do ensino jurídico.

Assim, ao se chegar neste momento do trabalho, conclui-se que, ao analisar toda a questão social que proporcionou o pioneirismo da mulher pelotense dentro do espaço jurídico, ao revisitar a história da Faculdade de Direito de Pelotas-RS, instituição consolidada no ensino jurídico, está-se exercitando o proposto pela atividade acadêmica, ou seja, contribuir na construção e preservação da história de uma cidade (Pelotas-RS) e de uma instituição, a qual está prestes a concluir seu centenário, demonstrando o pioneirismo de suas alunas.

\section{Referências}

ABRAHÃO; Maria Helena Menna Barreto (Org.). A Aventura (auto)biográfica: teoria e empíria. Porto Alegre: EDUPURCS, 2004. 
BOSI, Ecléa. Memória e Sociedade: lembrança de velhos. São Paulo: Companhia das Letras, 1994.

BURKE, Peter. O que é história cultural? Rio de Janeiro: Jorge Zahar Editor, 2005.

FÈLIX, Loiva Otero. História de vida do Ministério Público do Rio Grande do Sul: rememoração para o futuro. Porto Alegre: Procuradoria de Justiça. Projeto Memória, 2000.

GAARDER, Jostein. O mundo de Sofia. São Paulo: Círculo do Livro, 1991.

GERTUM, Felipe Assumpção. Heloisa Assumpção Nascimento entrevistada por Felipe Gertum (Parte I). Diário da Manhã, Pelotas, 15 maio 2005.

GERTUM, Felipe Assumpção. A primeira Dama da História de Pelotas (Parte II). Diário da Manhã, Pelotas, 22 maio 2005.

INSTITUTO NACIONAL JOAQUIM AUGUSTO DE ASSUMPÇÂO. A grande escritora e historiadora de Pelotas. Diário da Manhã, Pelotas, 12 maio 2005.

LIMA, Rosah Russomano de Mendonça. A libertação social da mulher: Discurso da oradora oficial - Colação de Grau dos Bacharéis de Direito de 1947. p. 6.

LOPES, Eliane M. T.: GALVÃO, Ana Maria de O. História da Educação. Rio de Janeiro: DP\&A, 2001.

LOURO, Guacira Lopes. Gênero, sexualidade e educação: uma perspectiva pósestruturalista. Petrópolis: Vozes, 1997.
MAGALHÃES, Mário Osório. História e tradição da cidade de Pelotas. Caxias do Sul: Gráfica da UCS, 1981.

NASCIMENTO, Heloisa Assumpção. Reminiscências acadêmicas. Jornal Diário Popular, Pelotas, 22 ago. 1982.

PERROT, Michelle. Mulheres públicas. Tradução de Roberto Leal Ferreira. São Paulo: Fundação Editora da UNESP, 1998.

. Minha história das mulheres. Tradução de Ângela M. S. Côrrea. São Paulo: Contexto, 2007.

RELATÓRIO DO GRÊMIO ACADÊMICO JURÍDICO. Período de junho de 1937 a junho de 1938.

SCOTT, Joan. Gênero: uma categoria útil de análise histórica. Educação e Realidade, Porto Alegre, v.16, n.2. p.522, 1999.

TAMBARA, Elomar. A educação feminina no Brasil ao final do século XIX. Revista História da Educação, Pelotas, v.1, 1997.

TILL, Rodrigues. História da Faculdade de Direito de Porto Alegre 1900/2000. Porto Alegre: Martins Livreiro, 2000.

VILLAR, Waleska Ribeiro. A casa de Bruno Lima: uma história da Faculdade de Direito de Pelotas (1918-1965). 2004. Dissertação (Mestrado em Educação) - Faculdade de Educação, Universidade Federal de Pelotas, Pelotas. 